\title{
Great flood and aeroallergen sensitization in children with asthma and/or allergic rhinitis
}

\author{
Nualanong Visitsunthorn,${ }^{\star}$ Wanwipa Chaimongkol, ${ }^{\star}$ Kittipos Visitsunthorn, ${ }^{\star}$ Punchama Pacharn,${ }^{\star}$ Orathai Jirapongsananuruk ${ }^{\star}$
}

\begin{abstract}
Background: Flooding may affect aeroallergen sensitization.

Objective: To evaluate aeroallergen sensitization in children with asthma and/or allergic rhinitis (AR) by skin prick test (SPT) before and after the great flood of 2011 in Bangkok, Thailand.

Methods: The study was performed retrospectively in asthma and/or AR children (aged 0-18 years) in Siriraj Hospital, Bangkok, Thailand from 2009 to 2013. All of the cases received SPT with common aeroallergens.

Results: SPTs were performed from 2009-2013 in a total of 2,010 asthma and/or AR children and 58.2\% and 60.5\% showed positive results, respectively. Poly-sensitization to aeroallergens was found in $67.5 \%$ of asthma and $67.0 \%$ of AR SPT-positive patients. In the study period, Dermatophagoides pteronyssinus $(D p)$ and Dermatophagoides ferinae (Df) were the most common causes of aeroallergen sensitization (82.4\% and $76.5 \%$, respectively), followed by American cockroach (43.5\%). After the severe flood in Bangkok in 2011, the trend of sensitization to American cockroach, Bermuda grass, Johnson grass, and Cladosporium spp. significantly decreased. However, the trend of sensitization to dog and Alterneria allergens in 2010 studied cases, significantly increased. During the study period, mean wheal diameter (MWD) of dog SPT was significantly associated with asthma severity, while the MWD of DP SPT was significantly associated with AR severity.
\end{abstract}

Conclusions: The aeroallergen sensitizations patterns had changed from previous years compared to the year during or after the flood. Thus, the great flood may have had a major impact on types of sensitization and the clinical patterns of airway allergy. Further confirmed by a prospective study is warranted.

Keywords: aeroallergen sensitization, asthma, allergic rhinitis, great flood, skin prick test

\section{From:}

* Division of Allergy and Clinical Immunology, Department of Pediatrics, Faculty of Medicine Siriraj Hospital, Mahidol University, Bangkok, Thailand

\section{Corresponding author:}

Nualanong Visitsunthorn

Division of Allergy and Immunology, Department of Pediatrics

Faculty of Medicine Siriraj Hospital, Mahidol University 2 Wanglang Road, Bangkoknoi, Bangkok 10700, Thailand

E-mail: nualanongv@yahoo.com

\section{Introduction}

Respiratory allergy, including asthma and allergic rhinitis (AR), is the most common allergic manifestation, representing a major health problem. The prevalence of allergic diseases has been increasing worldwide over the last three decades. ${ }^{1,2}$ Allergen exposure causes sensitization and the development of allergy symptoms in allergy-prone children. ${ }^{3}$ The majority of patients with asthma or chronic rhinitis have aeroallergen sensitization. ${ }^{3}$ Allergen sensitization is associated with an early age of onset and more severe symptoms (itchy nose, sneezing, nasal discharge, itchy eye, and watery eye) in patients with chronic rhinitis. ${ }^{3}$ Aeroallergen sensitization also associates with asthma severity..$^{4-6}$ Previous studies have shown that an increase in wheal size and the number of allergens to which a person is sensitized correlates with an increase in the severity of rhinitis and asthma. ${ }^{4,6}$

Allergen sensitization is demonstrated by the presence of serum-specific immunoglobulin E (sIgE) to allergens. Allergen sensitization can also be demonstrated in vivo by allergen skin prick test (SPT) and in vitro by serum sIgE levels. SPT is a reliable method for diagnosing IgE-mediated allergic diseases, 
as it is minimally-invasive, inexpensive, provides immediate results, and is easy to perform by trained health professionals. In contrast, diagnosis by serum allergen-specific IgE is more expensive and results take two to three days. In patients who cannot undergo SPT, such as patients who have extensive eczema, dermographism, urticaria, or who have taken antihistamines or other medications that interfere with the proper interpretation of SPT results, the measurement of sIgE may be useful. ${ }^{7,8}$

Bangkok, the capital of Thailand, is prone to flooding since it is located in lowland near the Chao Phraya River delta. In October 2010, limited flooding affected Bangkok and its surrounding areas. That flood lasted for only a few weeks. A year later, a severe flood occurred. It began on 25 July 2011 and continued until 16 January 2012, lasting for 175 days and claiming 815 lives. $^{9}$ Flooding affected provinces in northern, northeastern, and central Thailand along the Mae Klong and Chao Phraya Rivers. This severe and prolonged disaster has been described as the worst flooding in Thailand in recorded history in terms of the scope of the flooding and the number of people affected.

Flooding may affect the trend of allergen sensitization. Damp and warm environments are suitable for promoting mold growth during and after a flood. ${ }^{10}$ Water damage in flooded homes has been known to increase mold contamination, and exposure to mold can lead to adverse health effects, including asthma, allergies, and other respiratory problems. Fungi was shown to be common in homes after flooding, including Aspergillus, Cladosporium, Penicillium, Trichoderma, and Paecilomyces genera. ${ }^{11,12}$

Changes in bacterial and fungal community compositions in flooded homes 2-3 months after the 2011 Bangkok flood suggest a persistent impact of flooding, despite nearly all of the homes having completed or nearly completed remediation. ${ }^{13}$

The aim of this study was to evaluate aeroallergen sensitization in children with asthma and/or allergic rhinitis by skin prick test before and after the great flood of 2011 in Bangkok, Thailand.

\section{Methods}

Medical records of children (aged 0-18 years) that were clinically diagnosed with asthma and/or AR at the Pediatric Allergy Clinic, Faculty of Medicine Siriraj Hospital and who received SPT with common aeroallergens during the 2009 to 2013 study period were reviewed. The protocol for this study was approved by the Siriraj Institutional Review Board (SIRB). The severity of asthma was classified according to the Global Initiative for Asthma (GINA) guidelines. ${ }^{14}$ The severity of allergic rhinitis was classified according to the Allergic Rhinitis and its Impact on Asthma (ARIA) guidelines. ${ }^{15}$

SPTs of common aeroallergen extracts (ALK-Abelló A/S, Hørsholm, Denmark), including indoor allergens [Dermatophagoides pteronyssinus (Dp), Dermatophagoides farinae (Df), American cockroach, German cockroach, cat dander, dog epithelia, Alternaria spp., Cladosporium spp., Penicillium spp., Aspergillus spp., and Curvularia spp.] and outdoor allergens (Bermuda grass, Johnson grass, careless weeds, and acacia) were evaluated.
Skin tests were performed with metal lancets by trained health professionals. Histamine dihydrochloride $(10 \mathrm{mg} / \mathrm{mL})$ and $50 \%$ glycerosaline solution were used as positive and negative controls, respectively. Regarding the skin prick method, the needle was dipped into a drop of extract and was then used to prick the epidermis. SPT results were recorded 10 and 15 minutes after pricking with histamine and other allergens, respectively. The mean wheal diameter (MWD) of each extract was calculated from the sum of the widest wheal diameter plus the perpendicular diameter and divided by two. The SPT result was defined as positive if the MWD was at least $3 \mathrm{~mm}$ larger than that of the negative control.

Patients were considered to be mono-sensitized or poly -sensitized if they had one or more kind of allergen sensitization, respectively. Demographic and clinical characteristics of patients, including age, gender, age at onset, severity of asthma and/or AR, and result of SPT, were collected and analyzed. Associations between age of onset and MWD and severity of disease and MWD were analyzed.

\section{Statistical analysis}

Statistical analysis was performed using PASW Statistics version 18.0 (SPSS, Inc., Chicago, IL, USA). Demographic and clinical characteristics data are presented as median (range) for continuous data and as number (percentage) for categorical data. Chi-square test was used to compare categorical variables. Analysis of trends was performed using the chi-squared test for trend. The Mann-Whitney U test was used to compare non-normally distributed variables between groups. Associations between age of onset and MWD and severity of disease and MWD were analyzed using Spearman's rho correlation. A $p$-value $<0.05$ was regarded as being statistically significant.

\section{Results \\ Characteristics of the studied population}

Aeroallergen SPTs were performed in 2,010 children clinically diagnosed as having asthma and/or AR from 2009 to 2013 (339, 361, 324, 493, and 493 cases in 2009, 2010, 2011, 2012 , and 2013, respectively). The median age of patients was $7.2(0.5-17.9)$ years and the majority of patients $(62.2 \%)$ were male. Demographic and clinical characteristics are shown in Table 1. Asthma was found in 778 cases (38.7\%). Most of those cases had mild persistent asthma (72.6\%), followed by mild intermittent $(11.8 \%)$, moderate persistent (14.9\%), and severe persistent asthma ( $0.7 \%)$. Only $0.7 \%$ of asthma cases had severe asthma. In 1,879 allergic rhinitis cases $(93.5 \%$ of the study population), mild persistent was the most common severity (64.6\%), followed by mild intermittent (20.9\%) and moderate to severe persistent (12.0\%). Combined asthma and AR was found in $32.2 \%$ of patients. Asthma alone was found in $6.5 \%$ and $\mathrm{AR}$ alone was found in $61.3 \%$ of cases. Comorbid AR was found in $83.2 \%$ of cases diagnosed with asthma, while asthma was found in $52.3 \%$ of cases diagnosed with AR.

The prevalence of mild intermittent asthma in 2009 was significantly higher than in 2012 (20.2\% vs. 8.2\%, respectively; $p=0.02$ ). The prevalence of moderate to severe persistent allergic rhinitis in 2012 was significantly lower than in 2009 
and 2013 ( $7.2 \%$ vs. $18.5 \%$ and $14.0 \%$, respectively; $p<0.001)$. No significant difference was found in other severities of asthma

Table 1. Demographic and clinical characteristics of the study population $(\mathrm{N}=2,010)$

\begin{tabular}{lc}
\hline Characteristics & n (\%) or median (range) \\
\hline Male & $1,250(62.2 \%)$ \\
\hline Age, years & $7.2(0.5-17.9)$ \\
\hline Age at onset of asthma, years & $2.0(0.1-14.0)$ \\
\hline Age at onset of allergic rhinitis, years & $4.0(0.1-14.0)$ \\
\hline Asthma* (n=778) & $92(11.8 \%)$ \\
\hline - Mild intermittent & $565(72.6 \%)$ \\
\hline Mild persistent & $116(14.9 \%)$ \\
\hline Moderate persistent & $5(0.7 \%)$ \\
\hline Severe persistent & \\
\hline Allergic rhinitis ${ }^{*}(\mathrm{n}=1,879)$ & $393(20.9 \%)$ \\
\hline - Mild intermittent & $1,213(64.6 \%)$ \\
\hline Mild persistent & $47(2.5 \%)$ \\
\hline
\end{tabular}

${ }^{\star}$ Clinical diagnosis by allergist and allergic rhinitis during the 2009 to 2013 study period, as shown in Table $\mathbf{2 a}$ and $\mathbf{2 b}$.

\section{Aeroallergen sensitization}

The overall prevalence of positive aeroallergen sensitization in asthma and AR patients was $58.2 \%$ and $60.5 \%$, respectively. Poly-sensitization to aeroallergens was found in the majority of cases (67.5\% of asthma, $67.0 \%$ of AR), as shown in Figure 1. There was no significant difference in the percentage of positive SPTs to aeroallergens (for both mono- and poly-sensitization) between asthma and AR patients $(p=0.29$ and $p=0.83$, respectively). There was also no significant difference in the percentage of mono- or poly-sensitization to aeroallergens among asthma alone, $\mathrm{AR}$ alone, or asthma with $\mathrm{AR}(p=0.35)$.

A positive SPT was found in more than half of patients each year from 2009 to 2013. When comparing the distribution of SPT results over the 5-year period, we found the prevalence of positive SPT to be significantly higher in 2009 than in 2012 (65.8\% vs. $55.8 \%$; $p=0.02$ ). The percentage of positive SPT was not significantly different among the different classifications of asthma severity $(p=0.10)$. Among cases with mild AR, the percentage of negative SPT was significantly higher than the percentage of positive SPTs $(26.0 \%$ vs. $17.6 \% ; p<0.01)$. There was no significant difference between percentage of mono- and poly-sensitization among the 5 studied years $(p=0.23)$. The percentage of mono- and poly-sensitization was not significantly different among different levels of asthma and AR severity ( $p=0.63$ and $p=0.08$, respectively). A comparison of aeroallergen sensitization in children with asthma and/or

Table 2. Severity of asthma and allergic rhinitis in the study population during the 2009 to 2013 study period

2a. Severity of asthma during the 2009 to 2013 study period

\begin{tabular}{|c|c|c|c|c|c|}
\hline \multirow[t]{2}{*}{ Asthma severity } & \multicolumn{5}{|c|}{ Number of cases } \\
\hline & 2009 & 2010 & 2011 & 2012 & 2013 \\
\hline Mild intermittent & $25(20.2 \%)^{*}$ & $20(13.0 \%)$ & $14(11.1 \%)$ & $15(8.2 \%)^{*}$ & $15(9.1 \%)$ \\
\hline Mild persistent & $78(62.9 \%)$ & $105(68.2 \%)$ & $97(77.0 \%)$ & $138(75.4 \%)$ & $128(77.6 \%)$ \\
\hline Moderate to severe intermittent & $18(14.5 \%)$ & $28(18.2 \%)$ & $14(11.1 \%)$ & $30(16.4 \%)$ & $22(13.3 \%)$ \\
\hline Moderate to severe persistent & $3(2.4 \%)$ & $1(0.6 \%)$ & $1(0.8 \%)$ & $0(0 \%)$ & $0(0 \%)$ \\
\hline Total & $124(100 \%)$ & $154(100 \%)$ & $126(100 \%)$ & $183(100 \%)$ & $165(100 \%)$ \\
\hline
\end{tabular}

* Significant difference in prevalence of mild intermittent asthma in the year 2009 s $2012, \mathrm{p}=0.02$

2b. Severity of allergic rhinitis during the 2009 to 2013 study period

\begin{tabular}{|c|c|c|c|c|c|}
\hline \multirow[t]{2}{*}{ Allergic rhinitis severity } & \multicolumn{5}{|c|}{ Number of cases } \\
\hline & 2009 & 2010 & 2011 & 2012 & 2013 \\
\hline Mild intermittent & $58(18.8 \%)$ & 77 (23.5\%) & $57(18.9 \%)$ & $116(21.2 \%)$ & $71(16.8 \%)$ \\
\hline Mild persistent & $187(60.7 \%)$ & $206(63.0 \%)$ & $206(68.4 \%)$ & $294(63.9 \%)$ & $211(66.6 \%)$ \\
\hline Moderate to severe intermittent & $6(1.9 \%)$ & $6(1.8 \%)$ & $6(2.0 \%)$ & $17(3.7 \%)$ & $11(2.6 \%)$ \\
\hline Moderate to severe persistent & $57(18.5 \%)^{\star}$ & $38(11.6 \%)$ & $32(10.6 \%)$ & $33(7.2 \%)^{\star}$ & $59(14.0 \%)^{*}$ \\
\hline Total & $308(100 \%)$ & $327(100 \%)$ & $301(100 \%)$ & $460(100 \%)$ & $422(100 \%)$ \\
\hline
\end{tabular}

${ }^{\star}$ Significant difference in prevalence of moderate to severe persistent allergic rhinitis in the year 2012 vs 2009 and 2012 vs 2013 , p $<0.001$ 
allergic rhinitis during the 2009 to 2013 study period is presented in Figure 2. During the overall 5-year study period, $D p$ and $D f$ were the most common aeroallergens to which patients were sensitized (mean sensitization $82.4 \%$ and 76.5\%, respectively), followed by American cockroach (43.5\%), German cockroach (40.7\%), Bermuda grass (22.6\%), cat (19.9\%), dog (15.9\%), Johnson grass (15.3\%), Alternaria spp. (14.0\%), acacia $(11.2 \%)$, careless weed $(8.7 \%)$, Cladosporium spp. (8.1\%), Penicillium spp. (6.6\%), Curvularia spp. (5.7\%), and Aspergillus spp. (4.2\%).

The trend of sensitization for American cockroach, Bermuda grass, Johnson grass, and Cladosporium spp. significantly decreased from 2009 to 2013 ( $p<0.001,<0.001,0.009$, and 0.004, respectively), as shown in Figure 3. In contrast, sensitization for dog and Alterneria spp. significantly increased from 2009 to 2013 ( $p<0.001)$, especially after the floods in 2010-2011.
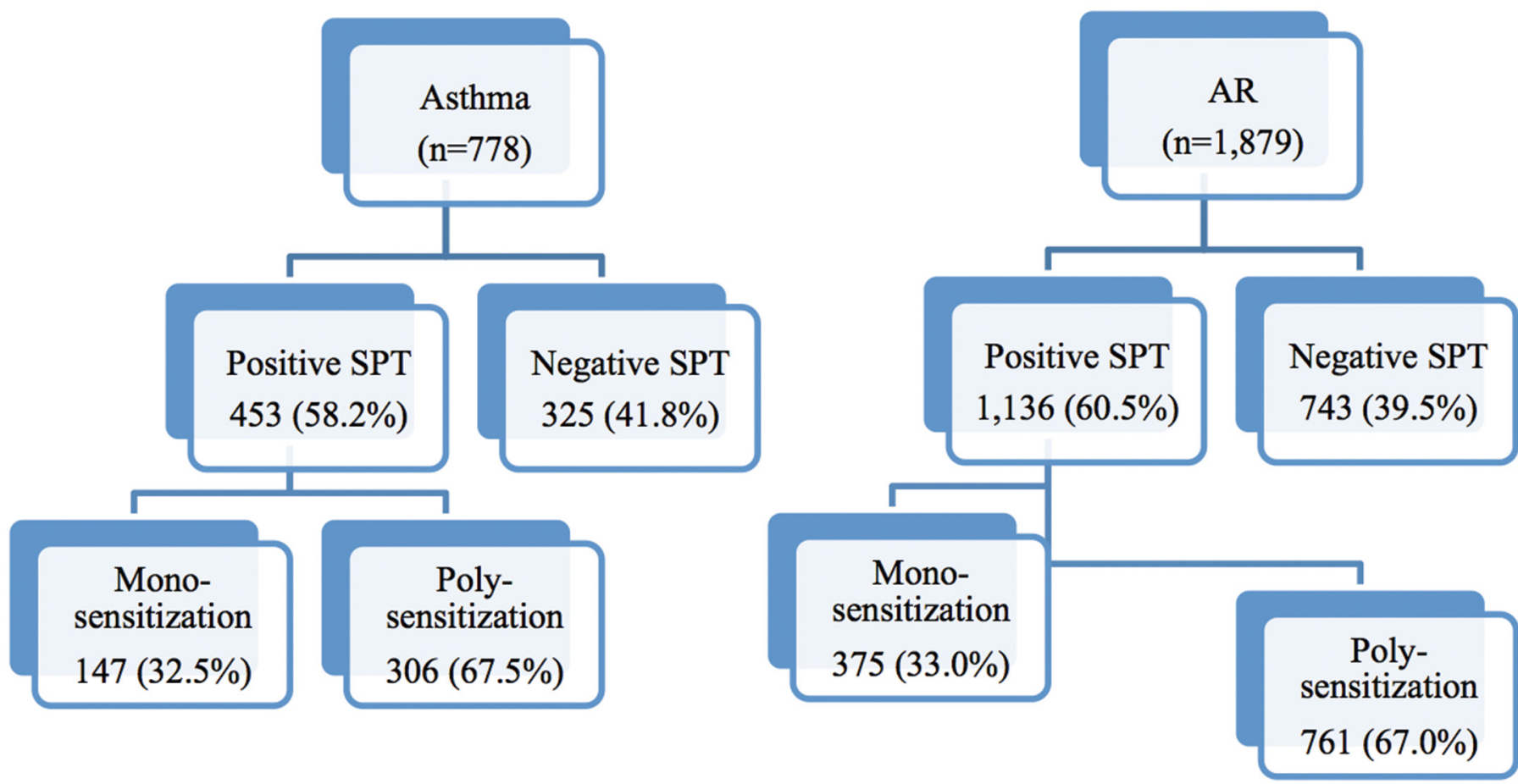

Figure 1. Results of aeroallergen sensitization by skin prick test (SPT) in asthma and allergic rhinitis patients

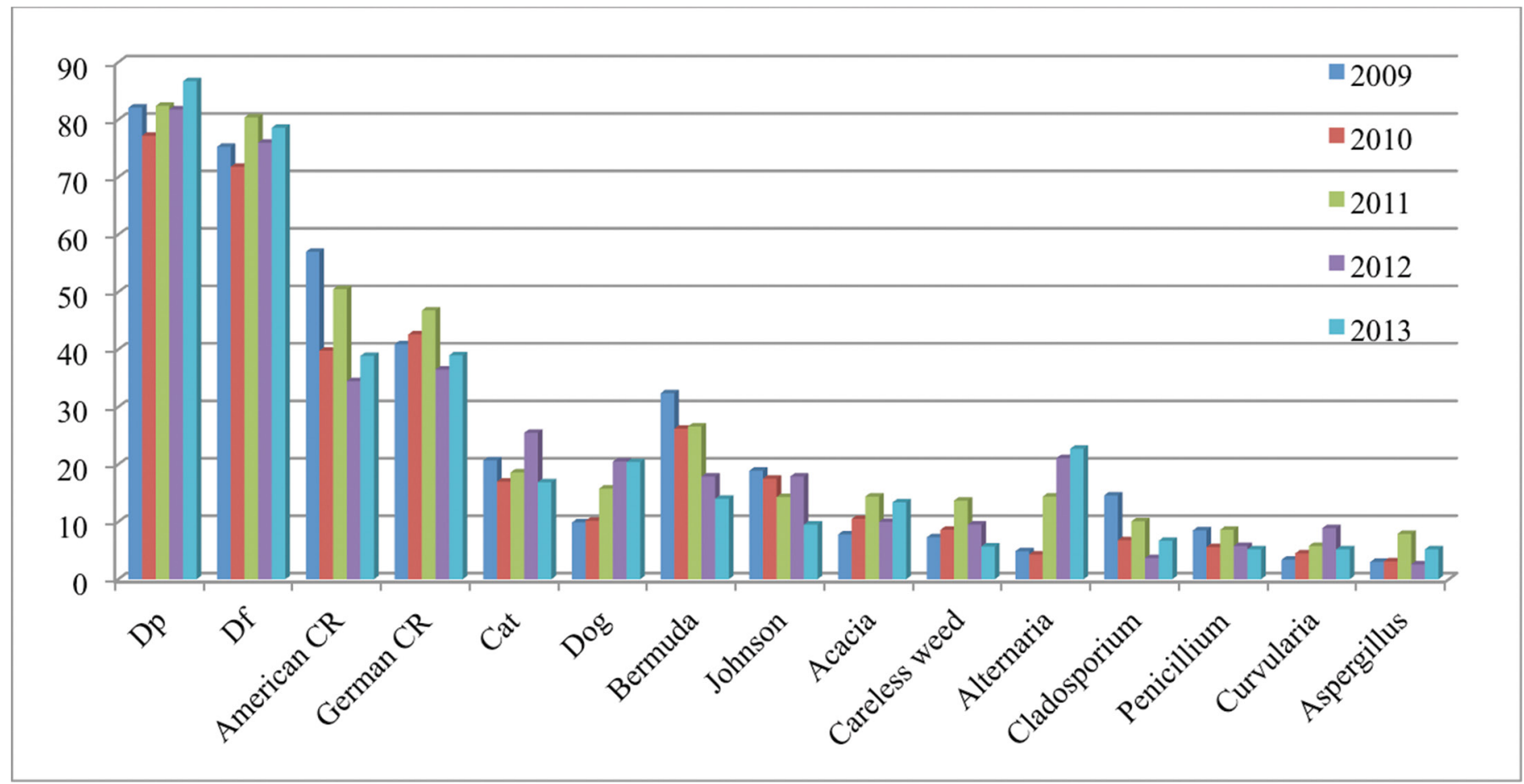

Figure 2. Comparison of aeroallergen sensitization in children with asthma and/or allergic rhinitis 
Among mono-sensitization cases, the most common allergen to which patients were sensitized was house dust mite (78.2\%), followed by American cockroach (7.3\%), German cockroach (4.7\%), Bermuda grass (4.0\%), cat (3.3\%), Johnson grass (2.0\%), Cladosporium spp. (1.9\%), careless weed $(0.9 \%)$, Penicillium spp. (0.9\%), Alternaria spp. (0.5\%), acacia (0.5\%), and $\operatorname{dog}(0.3 \%)$. House dust mite was also the most common allergen in poly-sensitization patients (90.5\%), followed by American cockroach (61.5\%), German cockroach (52.9\%),
Bermuda grass (31.9\%), cat (28.2\%), dog (23.7\%), Johnson grass (22.1\%), Alternaria spp. (18.6\%), acacia (14.8\%), careless weed (11.3\%), Cladosporium spp. (10.2\%), Penicillium spp. (8.5\%), Curvularia spp. (7.6\%), and Aspergillus spp. (5.7\%).

The median age at onset for non-atopic asthma (negative SPT) was significantly younger than that of atopic asthma (positive SPT) [1.5 (0.1-13.0) vs. 2.0 (0.2-14.0) years; $p<0.01]$ The median age at onset for non-AR (negative SPT) was also significantly younger than that of AR (positive SPT)
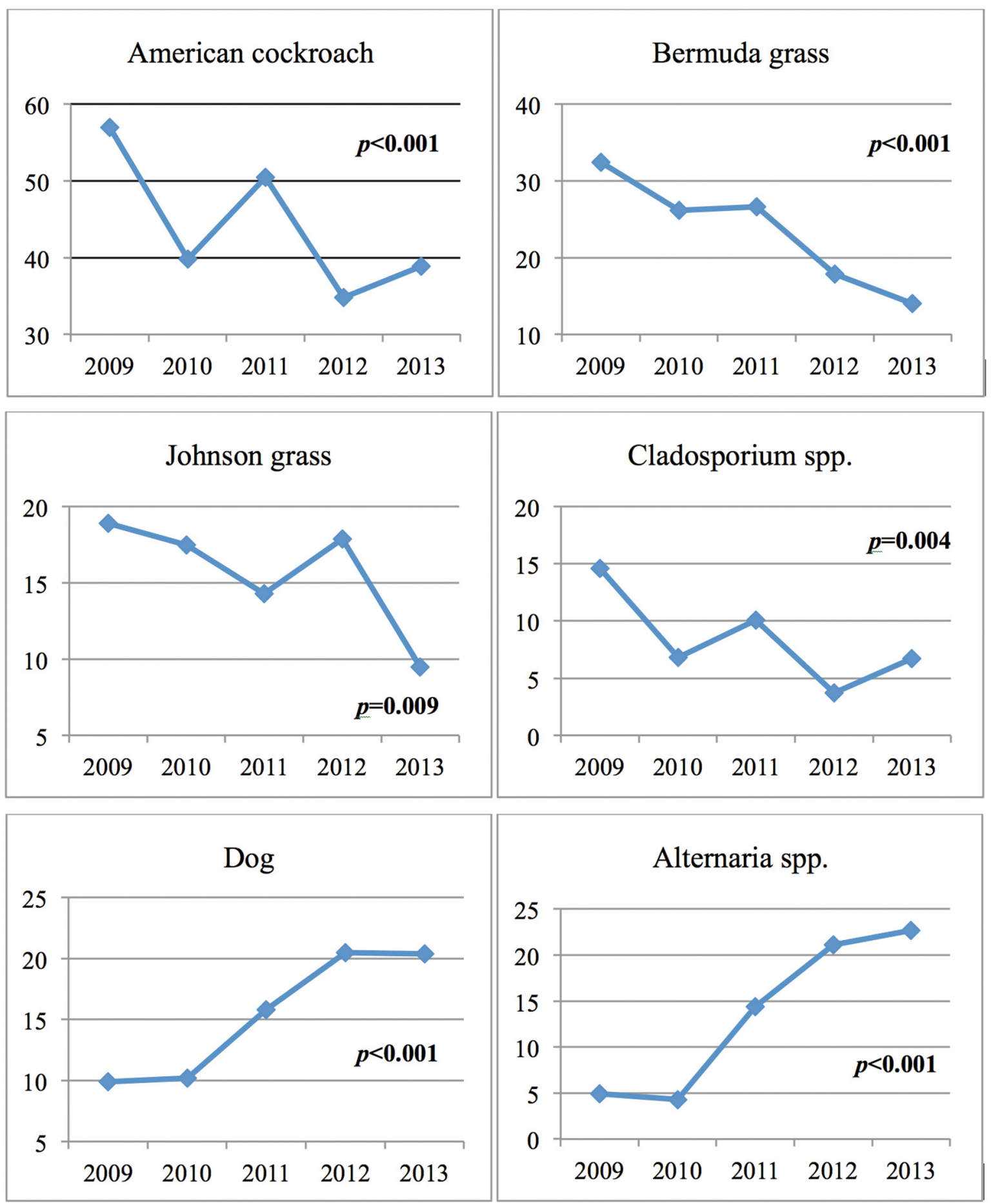

Figure 3. Trend of aeroallergen sensitization in children with asthma and/or allergic rhinitis during the 2009 to 2013 study period (before and after the severe flood in Bangkok, Thailand in 2011) 
Table 3. Comparison between mean wheal diameter and disease severity

3a. Comparison between mean wheal diameter and asthma severity

\begin{tabular}{|c|c|c|c|}
\hline \multirow{3}{*}{ Allergen } & \multicolumn{2}{|c|}{ Mean wheal diameter, $\mathrm{mm}(\min -\max )$} & \multirow{3}{*}{ p-value } \\
\hline & \multicolumn{2}{|c|}{ Asthma severity } & \\
\hline & Mild intermittent and mild persistent & Moderate to severe persistent & \\
\hline$D p(\mathrm{n}=362)$ & $7.5(3.0-30.0)$ & $7.5(3.0-20.0)$ & 0.39 \\
\hline$D f(\mathrm{n}=328)$ & $8.5(3.0-27.5)$ & $8.0(3.0-22.5)$ & 0.76 \\
\hline American CR $(\mathrm{n}=198)$ & $3.5(3.0-13.5)$ & $4.0(3.0-14.0)$ & 0.10 \\
\hline German CR $(n=128)$ & $4.0(3.0-11.0)$ & $4.0(3.0-10.0)$ & 2.93 \\
\hline Cat $(n=92)$ & $4.5(3.0-13.0)$ & $4.8(3.0-15.0)$ & 0.72 \\
\hline $\operatorname{Dog}(n=77)$ & $3.5(3.0-10.50)$ & $4.0(3.0-7.5)$ & 0.04 \\
\hline Bermuda grass $(n=109)$ & $3.0(3.0-17.5)$ & $3.5(3.0-11.0)$ & 0.11 \\
\hline Johnson grass $(\mathrm{n}=68)$ & $3.5(3.0-11.5)$ & $3.5(3.0-9.0)$ & 0.96 \\
\hline Acacia $(n=36)$ & $3.0(3.0-7.0)$ & $3.5(3.0-6.5)$ & 0.76 \\
\hline Careless weed $(\mathrm{n}=30)$ & $3.0(3.0-5.5)$ & $3.0(3.0-4.0)$ & 0.57 \\
\hline Alternaria spp. $(\mathrm{n}=41)$ & $4.0(3.0-9.0)$ & $3.0(3.0-7.5)$ & 0.17 \\
\hline Penicillium spp. $(\mathrm{n}=18)$ & $3.0(3.0-6.0)$ & $3.0(3.0-4.0)$ & 0.91 \\
\hline Aspergillus spp. $(\mathrm{n}=17)$ & $3.0(3.0-5.0)$ & $3.0(3.0-3.0)$ & 0.71 \\
\hline Cladosporium spp. $(\mathrm{n}=22)$ & $3.0(3.0-8.0)$ & $3.0(3.0-4.5)$ & 0.77 \\
\hline Curvularia spp. $(\mathrm{n}=17)$ & $3.3(3.0-6.5)$ & $3.0(3.0-3.5)$ & 0.51 \\
\hline
\end{tabular}

$p$-value $<0.05$ indicates statistical significance

Abbreviations: Dp, Dermatophagoides pteronyssinus; Df, Dermatophagoides farina; CR, cockroach

3b. Comparison between mean wheal diameter and allergic rhinitis severity

\begin{tabular}{|c|c|c|c|}
\hline \multirow{3}{*}{ Allergen } & \multicolumn{2}{|c|}{ Mean wheal diameter, $\mathrm{mm}$ (min-max) } & \multirow{3}{*}{ p-value } \\
\hline & \multicolumn{2}{|c|}{ Allergic rhinitis severity } & \\
\hline & Mild intermittent and mild persistent & Moderate to severe intermittent and persistent & \\
\hline$D p(n=922)$ & $7.5(3.0-35.0)$ & $9.0(3.0-30.0)$ & $<0.01$ \\
\hline$D f(\mathrm{n}=856)$ & $8.0(3.0-27.5)$ & $8.5(3.0-27.5)$ & 0.14 \\
\hline American CR $(\mathrm{n}=486)$ & $4.0(3.0-14.0)$ & $4.0(3.0-10.5)$ & 0.78 \\
\hline German CR $(\mathrm{n}=328)$ & $4.0(3.0-15.0)$ & $4.0(3.0-14.5)$ & 0.97 \\
\hline Cat $(n=225)$ & $5.0(3.0-15.0)$ & $4.5(3.0-15.0)$ & 0.51 \\
\hline $\operatorname{Dog}(n=181)$ & $3.5(3.0-18.5)$ & $3.5(3.0-10.5)$ & 0.93 \\
\hline Bermuda grass $(\mathrm{n}=255)$ & $3.0(3.0-17.5)$ & $3.8(3.0-10.0)$ & 0.14 \\
\hline Johnson grass $(\mathrm{n}=174)$ & $3.5(3.0-20.0)$ & $3.0(3.0-11.5)$ & 0.56 \\
\hline Acacia $(\mathrm{n}=89)$ & $3.0(3.0-17.5)$ & $3.0(3.0-4.5)$ & 0.72 \\
\hline Careless weed $(\mathrm{n}=70)$ & $3.0(3.0-5.5)$ & $3.0(3.0-5.0)$ & 0.79 \\
\hline Alternaria spp. $(\mathrm{n}=113)$ & $4.0(3.0-15.0)$ & $3.0(3.0-8.5)$ & 0.47 \\
\hline Penicillium spp. $(\mathrm{n}=52)$ & $3.0(3.0-12.5)$ & $3.0(3.0-4.5)$ & 0.69 \\
\hline Aspergillus spp. $(\mathrm{n}=30)$ & $3.0(3.0-5.0)$ & $3.0(3.0-3.5)$ & 0.56 \\
\hline Cladosporium spp. $(\mathrm{n}=67)$ & $3.0(3.0-8.0)$ & $3.0(3.0-5.0)$ & 0.22 \\
\hline Curvularia spp. $(\mathrm{n}=45)$ & $3.5(3.0-6.5)$ & $3.0(3.0-4.5)$ & 0.43 \\
\hline
\end{tabular}


[3.0 (0.2-14.0) vs. $4.8(0.1-14.0)$ years; $p<0.01]$. The median age at onset for mono-sensitized asthma was younger than that of poly-sensitized asthma $[2.0(0.3-14.0)$ vs. $3.0(0.2-12.0)$ years], but no statistical significance was observed $(p=0.22)$. The median age of onset for mono-sensitized AR was significantly younger than that of poly-sensitized AR [4.0 (0.1-13.0) vs. 5.0 (0.1-14.0) years; $p<0.001]$.

Mild persistent severity was found in $74.2 \%$ and $70.4 \%$ of atopic and non-atopic asthma, respectively. The distribution of asthma severity was not different between atopic and non-atopic cases $(p=0.97)$. The number of cases with mild persistent rhinitis was not significantly different between allergic rhinitis and non-allergic rhinitis $(66.1 \%$ vs. $62.1 \%$, respectively; $p>0.05)$. The prevalence of mild intermittent severity was significantly higher in non-AR than in AR (26.0 vs. $17.6 \%$; $p<0.01$ ). The distribution of asthma severity was not different between mono-sensitized and poly-sensitized asthmatic patients $(p=0.62)$. Mild persistent severity was found equally among mono- and poly-sensitization asthma cases (74.3\% and $74.2 \%$, respectively). The distribution of AR severity was also not different between mono-sensitized and poly-sensitized asthma patients $(p=0.08)$. Mild persistent severity was $65.8 \%$ and $66.3 \%$ in mono- and poly-sensitization $\mathrm{AR}$, respectively.

No correlation between MWD and onset of asthma or AR was observed for any of the aeroallergens. When evaluating MWD compared with severity of asthma or AR, we found that larger MWD of dog SPT correlated with more severe asthma $(p=0.04)$ (Table 3a) and larger MWD of Dp SPT correlated with more severe AR $(p<0.01)$ (Table $3 b)$.

Aeroallergen sensitization distribution among the groups with asthma, AR, and combined asthma and AR showed that the presence of sensitization to more than one aeroallergen increased the risk of having coexistent asthma and AR (odds ratio: 1.1-1.2). However, the difference between having one and more than one aeroallergen did not achieve statistical significance $(p=0.76)$.

\section{Discussion}

The findings of the present study revealed that among Thai children with allergic respiratory diseases during the 2009 to 2013 study period, $D p(82.4 \%)$ and $D f(76.5 \%)$ were the most common aeroallergens to which patients were sensitized, followed by American cockroach (43.5\%) and German cockroach $(40.7 \%)$. A previous study found house dust mite to be the most common aeroallergen sensitization in Thai children with allergic respiratory disease, being seen in approximately $80 \%$ of positive SPT patients. ${ }^{16}$ American cockroach was the second most common aeroallergen sensitization in that study, being found in approximately $40 \%$ of positive SPT patients.

This study found that $60 \%$ of patients with asthma or AR had at least one positive SPT to aeroallergen. Of these positive SPT patients, $85 \%$ were poly-sensitized. This was consistent with previous studies in Thai children which had found that $61.6 \%$ of patients in 2004 and $64.6 \%$ of patients in 2009 with asthma had positive SPT results. ${ }^{17}$ Moreover, $63.2 \%$ of asthmatic children had positive SPTs $^{18}$ and $89 \%$ of atopic asthmatic children were poly-sensitized. ${ }^{16}$
A severe flood submerged vast areas of metropolitan Bangkok in July 2011 and flooding continued until January 2012. This study found no incremental increase in severity of asthma or AR in children from 2009 to 2013, which is different from the findings of a previous study that reported an incremental increase in asthma severity from 2004 to 2009. ${ }^{17}$ This difference may be explained by improvements in asthma management and patient education.

When we evaluated allergen sensitization, we found that the prevalence of sensitization to American cockroach, Bermuda grass, Johnson grass, and Cladosporium spp. significantly decreased from 2009-2013, while sensitization to dog and Alterneria spp. significantly increased. Sensitization to dog and Alterneria spp. started increasing after the 2010 flood in Bangkok. Increased sensitization continued through the severe flood in 2011 and for one year after the flood into 2012. A study conducted in Southern Thailand reported different findings. That study found an increase in the number of asthmatic children who were sensitized to American cockroach, Bermuda grass, and Johnson grass in 2004 and 2009, but their finding was not statistically significant. ${ }^{17}$ A study in Sweden found that sensitization by SPT to cat, dog, birch, and timothy increased significantly from 1994 to $2009 .{ }^{19}$ These changing allergen sensitizations may be attributable to global warming, which may affect aeroallergen distribution differently from area to area.

Another possible explanation for the decrease in sensitization to American cockroach, Bermuda grass, Johnson grass, and Cladosporium spp. allergens from 2009 to 2013 is the severe flooding that took place in Bangkok during 2011-2012. During flood conditions, newly hatched cockroaches die within 3 days. More mature cockroaches may migrate to nearby areas or succumb to starvation. Although adult cockroaches can survive for 20-30 days in flood conditions, they temporarily lose their ability to reproduce. In addition, Bermuda grass and Johnson grass die when submerged under flood water and Cladosporium spp. can also decrease during flood conditions. The aforementioned are all in contrast to Alternaria spp., an indoor fungal allergen that can easily enter residential buildings and settle in carpets, clothing, and on flat surfaces. It thrives in moist areas and can often be found in structures that have sustained water damage from plumbing leaks and floods. This may explain why sensitization to Alternaria spp. significantly increased after the flood. The increase in dog allergen sensitization may be explained by the decision by pet owners to keep their $\operatorname{dog}(\mathrm{s})$ indoors during the flood. Previous studies showed that sensitization to Alternaria alternata was a risk factor for respiratory arrest in children and young adults with asthma..$^{20,21}$ Patients with severe forms of asthma should now be more carefully monitored, since Alterneria spp. sensitization increased after the Bangkok floods.

This study found that more severe asthma was observed in patients with a larger MWD of dog allergen SPT, while more severe AR was observed in patients with a larger MWD of $D p$ SPT. We did not find any correlation between other types of allergen sensitization and respiratory allergy severity. The previous studies reported that sensitization to mold, cockroach, or cat was associated with asthma severity, ${ }^{22,23}$ but they did not mention wheal size. However, due to the small sample size, the 
results associated with wheal size in dog allergens should be interpreted with caution.

Our study showed no correlation between MWD and the onset of asthma or AR, and between MWD and the severity of asthma or AR. A previous study in the UK reported that increased SPT reactivity to aeroallergen is associated with increased risk of hospital admission, use of an inhaled steroid, and airway obstruction. ${ }^{24}$

A previous study in Thailand found that among atopic patients, the greater the number of allergens to which the patient is hypersensitive is associated with an increased risk of the coexistence of AR and asthma. ${ }^{25}$ Our results also showed that the greater the number of aeroallergens to which the patient is sensitized, the higher the risk of having combined asthma and AR, but the association was non-significant and without a graded effect.

This study has some mentionable limitations. First, the retrospective design of this study is inherently susceptible to data omission and inconsistencies in treatment among patients given that treatments change and evolve over time. Second, all evaluated patients were recruited from one center, which is also Thailand's largest tertiary care center. As such, patients seen at our clinic may have been more advanced and more difficult to treat, which means that these findings may not be generalizable to the general population. However, the current study population was substantial $(\mathrm{N}=2,010)$ and the evaluation period was 5 years, both of which strengthen the validity and value of our findings.

\section{Conclusion}

The aeroallergen sensitizations patterns had changed from previous years compared to the year during or after the flood. Thus, great flood may have had a major impact on types of sensitization and the clinical patterns of airway allergy. Further confirmation by a prospective study is warranted.

\section{Acknowledgements}

This study was supported by a Chalermprakiat Grant from the Faculty of Medicine Siriraj Hospital, Mahidol University and by NSTDA Chair Professor grant (P-1450624) funded by Crown Property Bureau. The authors gratefully acknowledge Ms. Julaporn Pooliam for assistance with statistical analysis.

\section{Conflict of interest declaration}

The authors hereby declare no personal or professional conflicts of interest regarding any aspect of this study.

\section{References}

1. Asher MI, Montefort S, Björkstén B, Lai CK, Stranchan DP, Weiland SK, et al. Worldwide time trends in the prevalence of symptoms of asthma, allergic rhinoconjunctivitis, and eczema in childhood: ISAAC Phase One and Three repeat multicountry cross-sectional surveys. Lancet. 2006;368:733-43.

2. Wong GW, Leung TF, Fok TF. ISAAC and risk factors for asthma in the Asia-Pacific. Paediatr Respir Rev. 2004;5 Suppl A:S163-9.
3. Li J, Huang Y, Lin X, Zhao D, Tan G, Wu J, et al. Influence of degree of specific allergic sensitivity on severity of rhinitis and asthma in Chinese allergic patients. Respir Res. 2011;12:95.

4. Zimmerman B, Feanny S, Reisman J, Hak H, Rashed N, McLaughlin FJ, et al. Allergy in asthma. I. The dose relationship of allergy to severity of childhood asthma. J Allergy Clin Immunol. 1988;81:63-70.

5. Craig TJ, King TS, Lemanske RF Jr, Wechsler ME, Icitovic N, Zimmerman RR Jr, et al. Aeroallergen sensitization correlates with PC(20) and exhaled nitric oxide in subjects with mild-to-moderate asthma. J Allergy Clin Immunol. 2008;121:671-7.

6. Haselkorn T, Borish L, Miller DP, Weiss ST, Wong DA. High prevalence of skin positivity in severe or difficult-to-treat asthma. J Asthma. 2006;43:74552.

7. Oppenheimer J, Nelson HS. Skin Testing. Ann All Asthma Immunol. 2006;96:S6-12

8. Canonica GW, Ansetegui IJ, Pawankar R, Schmid-Grendelmeier P, van Hage M, Baena-Cagnani CE, et al. A WAO-ARIA-GA2LEN consensus document on molecular-based allergy diagnostics. World Allergy Organ J. 2013;6:17. doi: 10.1186/1939-4551-6-17.

9. 24/7 Emergency Operation Center for Flood, storm and landslide. Flood, storm and landslide situation report. [cited 17 January 2012]. Available from: http://en.m.wikipedia.org/wiki/2011_Thailand_floods

10. Brandt M, Brown C, Burkhart J, Burton N, Cox-Ganser J, Damon S et al. Mold prevention strategies and possible health effects in the aftermath of hurricanes and major floods. MMWR Recomm Rep. 2006;55:1e27.

11. Fisk WJ, Lei-Gomez Q, Mendell MJ. Meta-analyses of the associations of respiratory health effects with dampness and mold in homes. Indoor Air. 2007;17:284-96.

12. Johanning E, Auger P, Morey PR, Yang CS, Olmsted E. Review of health hazards and prevention measures for response and recovery workers and volunteers after natural disasters, flooding, and water damage: mold and dampness. Environ Health Prev Med. 2014;19:93-9.

13. Pyrosequencing $\mathrm{P}$, Mhuantong W, Wongwilaiwalin S, Laothanachareon T, Eurwilaichitr L, Tangphatsornruang S, et al. Survey of Microbial Diversity in Flood Areas during Thailand 2011 Flood Crisis Using High-Throughput Tagged Amplicon Pyrosequencing. PLoS ONE 2005;10(5): e0128043.

14. van Weel C, Bateman ED, Bousquet J, Reid J, Grouse L, Schermer T, et al. Asthma management pocket reference 2008. Allergy. 2008;63:997-1004.

15. Bousquet J, Van Cauwenberge P, Khaltaev N; ARIA Workshop Group; World Health Organization. Allergic rhinitis and its impact on asthma. J Allergy Clin Immunol. 2001;108(5 Suppl):S147-334.

16. Kongpanichkul A, Vichyanond P, Tuchinda M. Allergen skin test reactivities among asthmatic Thai children. J Med Assoc Thai. 1997;80:69-75.

17. Yeunyoungviwat A, Koonrangsesomboon D, Sangsupawanich P. Recent 5 -year trends of asthma severity and allergen sensitization among children in southern Thailand. Asian Pac J Allergy Immunol. 2013;31:242-6.

18. Tuchinda M, Habananada S, Vareenil J, Srimaruta N, Piromrat K. Asthma in Thai children: a study of 2000 cases. Ann Allergy. 1987;59:207-11.

19. Warm K, Lindberg A, Lundbäck B, Rönmark E. Increase in sensitization to common airborne allergens among adults - two population-based studied 15 years apart. Allergy Asthma Clin Immunol. 2013;9:20.

20. O'Hollaren MT, Yunginger JW, Offord KP, Somers MJ, O'Connell EJ, Ballard DJ, et al. Exposure to an aeroallergen as a possible precipitating factor in respiratory arrest in young patients with asthma. N Engl J Med. 1991;324:359-63.

21. Plaza V, Serrano J, Picado C, Cosano J, Ancochea J, de Diego A, et al. Clinical characteristics of the fatal and near-fatal asthma in Alternaria alternata sensitized patients. Med Clin (Barc). 2003;121:721-4.

22. Gent JF, Kezik JM, Hill ME, Tsai E, Li DW, Leaderer BP. Household mold and dust allergens: exposure, sensitization and childhood asthma morbidity. Environ Res. 2012;118:86-93.

23. Wang J, Visness CM, Calatroni A, Gergen PJ, Mitchell HE, Sampson HA. Effect of environmental allergen sensitization on asthma morbidity in inner-city asthmatic children. Clin Exp Allergy. 2009;39:1381-9.

24. Carroll WD, Lenney W, Child F, Strange RC, Jones PW, Whyte MK, et al. Asthma severity and atopy: how clear is the relationship? Arch Dis Child. 2006;91:405-9.

25. Sritipsukho P. Aeroallergen sensitization among Thai children with allergic respiratory diseases: a hospital-based study. Asian Pac J Allergy Immunol. 2004;22:91-5. 